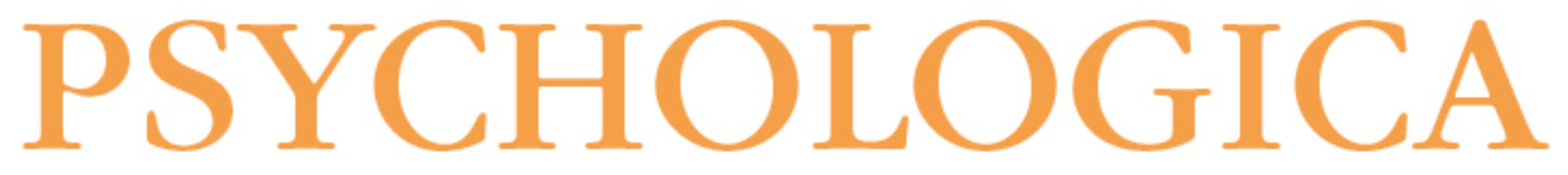

\title{
Derrota - conceito e avaliação: características psicométricas da versão portuguesa da Escala de Derrota (Defeat Scale)
}
Autor(es):
Carvalho, Serafim;
Paulo; Maia, Dulce
Publicado por: Imprensa da Universidade de Coimbra
URL persistente:
URI:http://hdl.handle.net/10316.2/5581
DOI:
DOI:http://dx.doi.org/10.14195/1647-8606_54_18
Accessed : $\quad$ 26-Apr-2023 15:24:19

A navegação consulta e descarregamento dos títulos inseridos nas Bibliotecas Digitais UC Digitalis, UC Pombalina e UC Impactum, pressupõem a aceitação plena e sem reservas dos Termos e Condições de Uso destas Bibliotecas Digitais, disponíveis em https://digitalis.uc.pt/pt-pt/termos.

Conforme exposto nos referidos Termos e Condições de Uso, o descarregamento de títulos de acesso restrito requer uma licença válida de autorização devendo o utilizador aceder ao(s) documento(s) a partir de um endereço de IP da instituição detentora da supramencionada licença.

Ao utilizador é apenas permitido o descarregamento para uso pessoal, pelo que o emprego do(s) título(s) descarregado(s) para outro fim, designadamente comercial, carece de autorização do respetivo autor ou editor da obra.

Na medida em que todas as obras da UC Digitalis se encontram protegidas pelo Código do Direito de Autor e Direitos Conexos e demais legislação aplicável, toda a cópia, parcial ou total, deste documento, nos casos em que é legalmente admitida, deverá conter ou fazer-se acompanhar por este aviso.

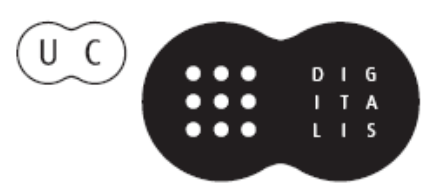




\section{NÚMERO 54}

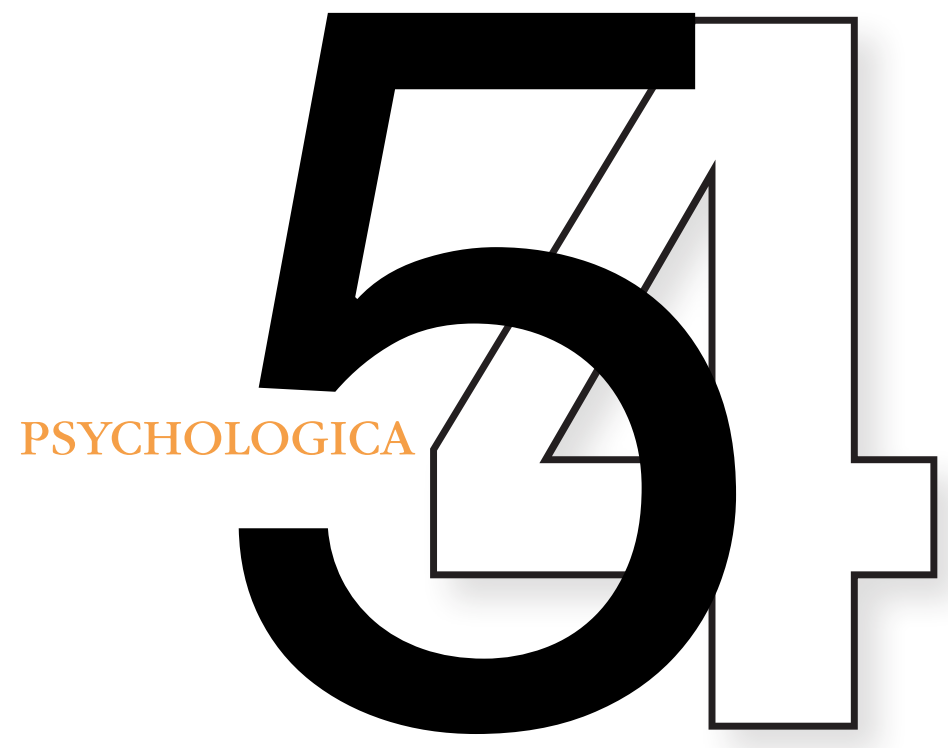

AVALIAÇÃO PSICOLÓGICA EM CONTEXTO CLÍNICO 


\title{
Derrota - conceito e avaliação: Características psico- métricas da versão portuguesa da Escala de Derrota (Defeat Scale)
}

\author{
Serafim Carvalho, ${ }^{1,2}$ José Pinto-Gouveia2, Paula Castilho², Paulo Pimente| ${ }^{3,4} \&$ Dulce Maia
}

\begin{abstract}
A teoria do posto social (social rank theory), no contexto da psicopatologia evolucionária, sugere que a derrota é uma resposta psicobiológica adaptativa presente sobretudo em situações de conflitos agonísticos. Estudos em animais e no homem demonstraram o impacto neurobiológico negativo das situações de derrota. No ser humano, o estado de derrota exprime o sentimento resultante de perdas na luta por objectivos importantes e de posto social. A Escala de Derrota (ED) foi desenvolvida por Gilbert e Allan (1998) com o objectivo de avaliar a intensidade da derrota. As propriedades psicométricas da ED foram avaliadas num grupo de estudantes $(n=609)$, num grupo da população geral $(n=406)$ e num grupo de doentes com depressão major $(n=106)$. A escala revelou uma estrutura unidimensional na análise factorial e uma boa consistência interna, entre .89 e .93, nos três grupos e em ambos os géneros. A estabilidade teste-reteste, a validade convergente com sintomatologia depressiva e a validade divergente com o suporte social e o optimismo, assim como a validade de construto mostraram-se adequadas. A presente versão da Escala de Derrota mostrou ter qualidades psicométricas adequadas para ser utilizada em populações clínicas e não clínicas.
\end{abstract}

PALAVRAS-CHAVE: Escala de Derrota, Características Psicométricas, Psicopatologia Evolucionária.

\section{INTRODUÇÃO}

A perspectiva evolucionária interpreta a psicopatologia como resultado da activação de estados cerebrais que evoluíram através de processos de selecção natural desempenhando um papel essencial na sobrevivência e adaptação ao meio ambiente. Assim, todas as espécies incluindo a humana, necessitam de

\footnotetext{
1 Hospital de Magalhães Lemos, E. P. E. - Porto - smicarval@gmail.com

2 CINEICC - Faculdade de Psicologia e Ciências da Educação da Universidade de Coimbra

3 Centro Hospitalar de Trás-os-Montes e Alto-Douro, E. P. E. - Vila Real

4 Universidade Lusófona - Porto
} 
sistemas evolutivos de resposta ao meio que são psicobiologicamente preparados e que the permitam detectar, reconhecer e responder a ameaças e a outros estímulos ambientais (Pinto-Gouveia, 2000). No homem, evoluindo em âmbitos sociais cada vez mais exigentes, foi particularmente benéfica a selecção de mecanismos reguladores dos relacionamentos e conflitos sociais entre conspecíficos. Na base da regulação emocional e comportamental humana encontram-se assim, estratégias filogeneticamente evoluídas e.g., luta, fuga, aceitação da derrota e subordinação, vinculação, capacidade para procurar e receber ajuda ou para elaboração de alianças.

\subsection{Conceito de Derrota}

Entre as estratégias de defesa, a subordinação e a derrota social têm sido particularmente estudadas no âmbito da teoria do posto social (social rank theory). $\mathrm{Na}$ competição entre conspecíficos por recursos fundamentais como território, alimentos ou oportunidades sexuais, ocorrem conflitos e lutas nos quais uns perdem e outros ganham. Price $(1969,1972)$ inicialmente baseado em estudos animais, propôs que sentimentos de inferioridade, estados de ansiedade, e particularmente estados depressivos podiam resultar de derrota competitiva em contextos sociais. Os animais que estão na iminência de perder ou perderam num conflito têm um mecanismo interno que inibe o comportamento desafiador. O contendor que percebeu que vai ter um revés pode ter uma de duas respostas fundamentais: lutar mais intensamente apesar da iminência de insucesso e risco de ferimentos graves ou morte, ou por outro lado emitir sinais ao oponente capazes de influenciar o estado mental deste e parar a agressão sem consequências maiores. Parece pois existir uma estratégia primitiva envolvendo modificações biológicas internas que automaticamente forçam o contendor em risco, a fugir, recuar ou submeter-se via comportamentos de submissão, reduzindo a propensão ao prosseguimento do conflito ou luta que não pode ganhar e reduzir a aspiração por esse objectivo (Gilbert \& Allan, 1998). Esta estratégia traduz o estado de derrota.

Os comportamentos de submissão devem ter impacto, quer para parar as aspirações próprias, mas também devem ser suficientemente claros para influenciar a mente do oponente e parar a agressão. Assim, a depressão seria a consequência deste impacto no próprio, que origina uma diminuição da auto-confiança, inibição de comportamentos de desafio e do desejo de obtenção de recursos. A derrota competitiva está associada a passividade, desinvestimento do ambiente e da procura de recursos (Price, 1972). É possível que no homem a percepção de derrota possa ser fundamental na diminuição da actividade dos sistemas de reforço, logo da ocorrência e manutenção do afecto depressivo e anedonia (Gilbert, 2000). 
A competição por recursos é, nos nossos dias, menos frequentemente agressiva e violenta sendo mais baseada na atracção social e formação de alianças. Porém, ser escolhido para parceiro sexual ou aliado é estar igualmente a competir, falhar nesta competição desencadeia os mesmos mecanismos da derrota (Gilbert, 2001).

Price e Sloman (1987) inicialmente denominaram "subrotina de desistência do comportamento ritual agonístico" (yelding subroutine of ritual agonistic behaviour) à resposta de derrota competitiva, mais tarde mudaram a designação para estratégia de subordinação involuntária (Price, Sloman, Gardner, Gilbert, \& Rohde, 1994). Porém, devido ao facto de existirem uma série de estratégias de subordinação involuntárias que não se relacionam com depressão (Gilbert, 2000), a designação foi de novo mudada para focar em particular a derrota, passando a denominar-se então estratégia de derrota involuntária (EDI) (Sloman \& Gilbert, 2000).

Verificou-se que em humanos a tendência à emissão de comportamentos de submissão estava relacionada com psicopatologia e.g., depressão, somatização, ansiedade e fobia social, sintomatologia obsessivo-compulsiva, ideação paranóide, sensitividade interpessoal, hostilidade e perturbações do comportamento alimentar (Allan \& Gilbert, 1997).

Um vasto número de estudos em animais, em roedores e primatas não humanos, revelaram que situações de derrota, social defeat, determinam um conjunto de efeitos específicos, quer biológicos (neuroendócrinos e imunológicos) quer do comportamento social (Von Holst, 1986; Meerlo, de Boer, Koolhaas, Daan, \& van den Hoofdakker, 1996), particularmente no comportamento exploratório e de procura de reforço (Henry, 1982). Assim, estudos laboratoriais em roedores mostraram que experiências de derrota competitiva repetidas resultaram em consequências fisiológicas e comportamentais que incluíam: diminuição da agressão ofensiva, (Lagerspetz \& Sandnabba, 1982); aumento das respostas defensivas (Frischknecht, Siegfried, \& Waser, 1982); diminuição do comportamento exploratório e aumento da reacção de imobilização ou freezing (Raab et al., 1986); perda de peso (Adams \& Boice, 1983); redução dos comportamentos apetitivos (Van de Poll, Smeets, Van Oyen, \& Van der Zwan 1982) e perturbação da aprendizagem de evitamento (Williams \& Lierle, 1988). Vários estudos animais demonstram ainda que o posto social tem efeitos muitos marcados na mortalidade a curto prazo e longo prazo em experiências de derrota (Blanchard \& Blanchard, 1990; Carobrez, Gasparotto, Buwalda, \& Bohus, 2002; Chuang et al., 2010). Numa revisão recente sobre efeitos psicobiológicos em contextos de ameaça ao posto social, quer em animais quer em humanos a autora conclui: "One powerful elicitor of changes in the autonomic, endocrine and immune systems is threat to social status." (Kemeny, 2009, p. 1). 
No homem, contextos sociais de derrota têm um forte impacto nos processos psicobiológicos internos como diminuição da serotonina e activação do eixo hipotálamo-hipófise-supra-renal (HHSR), com elevação do cortisol plasmático (Kemeny, 2009; Kennedy, 2002; Levitan, Vaccarino, Brown, \& Sapolsky, 2002). Igualmente vários estudos demonstram anomalias do HHSR, com aumento do cortisol plasmático e hiperactivação do sistema nervoso vegetativo parassimpático na depressão major (Levitan, Hasey, \& Sloman, 2000; McQuade \& Young, 2000; Nemeroff, 1998; Raadsheer, Hoogendijk, Stam, Tilders, \& Swaab, 1994) indicando tratar-se de um estado de stress crónico. Tal situação, a longo prazo determina efeitos adversos ao nível do sistema imunológico e pode causar alterações da neuroplasticidade cerebral (Sapolsky, 2000), embora um estudo posterior acerca deste efeito tenha produzido resultados controversos em avaliações post-mortem (Bao, Meynen, \& Swaab, 2008). Por outro lado alguns estudos revelam que, mesmo as formas menos graves de depressão, incluindo a distimia, se encontram associadas a anomalias neurofisiológicas (Griffiths, Ravindran, Merali, \& Anisman, 2000).

As pessoas deprimidas vêem-se a si próprias como inferiores i.e., tendem não só a fazer comparações sociais negativas mas também a adoptar um estereótipo comportamental de subordinação (Allan \& Gilbert, 1997; Carvalho, Pinto-Gouveia, Pimentel, \& Maia, 2007), parecendo ocorrer o mesmo na ansiedade e fobia social (Gilbert, 2000).

A estratégia de derrota involuntária (EDI), dispositivo de regulação emocional, cognitivo e comportamental desenvolvido ao longo da evolução, é então um estado final que requer um sistema de avaliação e.g., via comparação social, e um sistema comportamental e.g., via emissão de comportamentos de submissão.

A comparação social é uma estratégia evolucionária básica utilizada como analisador entre recursos próprios e os recursos dos oponentes. É utilizada por espécies territoriais, predominante nos répteis, nas aves e alguns mamíferos solitários como recurso do sistema de defesa territorial e particularmente na selecção intrasexual por espécies vivendo em grupo, é como que um sistema verificador do posto social e dos recursos potenciais ou de poder, resourceholding potencial (RHP), num conflito. Nos primatas, particularmente no homem a comparação social está ligada à avaliação do poder de atracção social, social attention holding power (SAHP), bem como ao comportamento assertivo e submisso (Gilbert, Price, \& Allan, 1995).

Em contexto clínico, apesar da derrota aparecer frequentemente ligada a percepções de baixo estatuto social (comparação social negativa), ela parece ter um efeito específico na determinação do humor. Sentimentos de derrota parecem 
ser mais determinantes para a ocorrência de depressão do que a percepção de baixo estatuto social isolada (Carvalho et al. submetido para publicação; Gilbert \& Allan, 1998). Viver ou ter crescido em ambientes aversivos, de pobreza, hostis, onde a pessoa é sistematicamente sujeita a conflitos, dominada e oprimida pode levar a perda de estatuto social e à necessidade de emissão comportamentos de submissão, bem como ao desenvolvimento de estratégias de comparação social negativa. A adopção da estratégia de derrota involuntária (EDI) prematura no ser humano pode ser atribuída a uma história familiar de pais punitivos e autoritários, violência física ou abuso sexual (Sloman \& Gilbert, 2000). Muitos doentes deprimidos, especialmente com perturbações depressivas crónicas (Andrews, 1998) tiveram experiências adversas na infância como, negligência, violência psicológica e física e/ou abuso sexual que perturbam o desenvolvimento e o funcionamento psicobiológico a longo prazo (Bifulco, Bernazzani, Moran, \& Jacobs, 2005; Rosenblum et al., 1994).

Tornou-se assim imprescindivel desenvolver uma estratégia empírica de investigação para testar as predições específicas dos modelos evolucionários, que passa também pelo desenvolvimento de escalas e questionários específicos, particularmente para avaliação da derrota.

A Escala de Derrota (ED) foi desenvolvida a partir do trabalho com doentes deprimidos e publicada por Gilbert e Allan (1998). A versão original da ED foi validada num grupo de estudantes $(n=302)$ e num grupo de doentes $(n=90)$, tendo sido avaliadas as suas propriedades psicométricas e estrutura factorial. Os autores conduziram uma análise de componentes principais com rotação oblíqua (Oblimin); na amostra de estudantes foram extraídos dois factores com eigenvalues superiores a 1.00 e explicando respectivamente $52.8 \%$ e $7.3 \%$ da variância. $\mathrm{Na}$ amostra de doentes ocorreu a mesma solução de dois factores, explicando $51.2 \%$ e $7.4 \%$ da variância. No entanto os autores, devido à forte correlação entre os 2 factores $(r=.58)$, ao facto dos três itens do segundo factor corresponderem aos itens cotados de forma inversa, bem como o conteúdo dos itens não aparentar carácter distintivo, efectuaram uma solução forçando um factor único. Desse modo, obtiveram um único factor com saturações nos itens iguais ou superiores a .45 sugerindo uma solução unidimensional. Foi então confirmada uma solução unifactorial, explicando $52.8 \%$ da variância total da escala no grupo de estudantes e $51.2 \%$ no grupo de doentes deprimidos.

A escala revelou uma consistência interna muito boa, com um alfa de Cronbach nos dois grupos e nos dois géneros entre .93 e .94. Os autores encontraram correlações elevadas com psicopatologia no grupo de doentes, particularmente com sintomatologia depressiva i.e., com o BDI $(r=.65)$ e com a BHS, Beck Hopelessness Scale $(r=.77)$; e com a CES-D, Centre for Epidemiological Studies Depression Scale ( $r$ 
= .73) no grupo de estudantes. Igualmente foram encontradas correlações significativas com variáveis evolucionárias: entrapment interno, entrapment externo, comparação social e comportamento de submissão com valores de $r$ de Pearson respectivamente de $.75, .66,-.59$ e .35 .

470 Desde a sua publicação a ED foi usada em vários estudos como medida do estado de derrota, quer em amostras clínicas quer em amostras da população geral (Gilbert et al., 2002; Martin, Gilbert, McEwan, \& Irons, 2006; Rasmussen et al., 2010; Shahmanesh et al., 2009; Sturman \& Mongrain, 2005; Taylor et al., 2010; Troop \& Baker, 2008; Willner \& Goldstein, 2001).

Num estudo envolvendo um grupo de doentes deprimidos e um grupo da população geral sem psicopatologia, utilizando variáveis de posto social i.e., derrota, entrapment (inibição da resposta de fuga), comportamento de submissão e comparação social, a sintomatologia depressiva foi sobretudo explicada pela derrota e pelo entrapment. A explicação parece ser a seguinte: se um indivíduo derrotado pode sair, fugir ou evitar a situação ou se submete e essa submissão é aceite pelo oponente, o indivíduo pode aceitar a derrota e recomeçar noutro lugar. A aceitação do desapontamento e da derrota promove a desactivação da estratégia de derrota involuntária e a psicopatologia é menos intensa. No caso em que o derrotado está também em entrapment o indivíduo não pode sair da situação e reverter a estratégia de derrota involuntária que se mantém persistentemente activada (Sloman \& Gilbert, 2000).

Tanto quanto é do nosso conhecimento não foram realizados estudos psicométricos da Escala de Derrota na população portuguesa particularmente em contexto da psicopatologia depressiva.

\section{OBJECTIVOS}

Na tentativa de ultrapassar a carência em medidas de avaliação dos estados emocionais de derrota, o presente estudo procura em primeiro lugar traduzir e adaptar para a língua portuguesa a ED. Em segundo lugar pretende investigar a sua estrutura factorial num grupo de estudantes, num grupo da população geral e num grupo de doentes com depressão major em relação às suas experiências de derrota. Em último lugar, o presente estudo pretende avaliar as propriedades psicométricas da estrutura factorial obtida, especificamente a análise dos itens e consistência interna, fidelidade teste-reteste e, ainda, explorar a validade convergente e divergente deste instrumento usando medidas de depressão, optimismo disposicional e suporte social. 


\section{METODOLOGIA}

\subsection{Participantes}

A amostra utilizada neste estudo foi constituída por 3 grupos de sujeitos: um grupo era formado por estudantes, outro constituído por sujeitos da população geral e outro grupo constituído por doentes com diagnóstico de episódio depressivo major seguidos em consulta externa de psiquiatria.

\section{Grupo de Estudantes}

Foi utilizada uma amostra de conveniência composta por 609 sujeitos (428 do género feminino e 181 do género masculino) provenientes de instituições públicas e privadas de Ensino Superior e de escolas profissionais da região Centro e Norte do País, a idade média foi de 20.7 anos ( $D P=2.9$ ) e a escolaridade média foi de 13.4 anos (DP = 1.6). Foi pedida autorização à direcção das instituições e após esta foram contactados professores de referência que permitissem a utilização de parte do seu tempo lectivo para a presente investigação. Os alunos foram informados e procedeu-se à marcação de datas. Nesse dia, os alunos presentes foram esclarecidos dos objectivos da investigação e foram convidados a participar, aqueles que aceitaram assinaram um termo de consentimento, realçando a participação voluntária e a confidencialidade. Os questionários foram preenchidos na presença de um dos investigadores.

\section{Grupo da População Geral}

Foi utilizada uma amostra de conveniência colhida entre trabalhadores de três empresas privadas e entre funcionários de três instituições públicas do Norte e Centro do país, composta por 406 sujeitos (248 do género feminino e 158 do género masculino), a idade média foi de 37.7 anos ( $D P=10.2$ ); sendo a escolaridade média de 12.9 anos (DP = 4.0). Foi pedida autorização à direcção das empresas e instituições, após a sua obtenção foram contactados quadros intermédios para a ligação aos trabalhadores e marcação de datas. Nesse dia, os trabalhadores foram esclarecidos dos objectivos da investigação e foram convidados a participar, aqueles que aceitaram assinaram um termo de consentimento, realçando a participação voluntária e a confidencialidade. Os questionários foram preenchidos no mesmo dia ou em data posterior na presença de um dos investigadores

\section{Grupo de Doentes}

O grupo de 106 doentes ( 78 do género feminino e 28 do género masculino) consistia em sujeitos com um novo episódio de depressão major que recorreram à consulta externa do Hospital de Magalhães Lemos E.P.E. - Porto, entre Janeiro 
de 2006 e Dezembro de 2006. A idade média foi de 37.9 anos (DP = 10.6); sendo a escolaridade média de 10.9 anos ( $D P=4.2$ ). Os doentes enviados pelo médico de família com diagnóstico de depressão e que na entrevista clínica confirmaram as suspeitas, foram sujeitos a avaliação diagnóstica de depressão major com a SCID-I (Structured Clinical Interview for DSM-IV Axis I Disorders) (First, Spitzer, Gibbon, \& Williams, 1996). Todos os doentes com o diagnóstico de episódio de depressão major e com BDI igual ou superior a 20 eram elegíveis para entrar no estudo. Aos doentes com diagnóstico de episódio depressivo major e sem critérios de exclusão (i.e., perturbação por dependência de substâncias e perturbações psicóticas) foi solicitada a sua participação na investigação e explicados os objectivos. Dos 115 doentes elegíveis, 5 não aceitaram participar e 4 faltaram na data marcada para o preenchimento do protocolo. Os doentes que aceitaram, assinaram o termo de consentimento, onde se realçava a voluntariedade da participação e confidencialidade das respostas. O presente projecto de investigação foi autorizado pela comissão de ética do Hospital de Magalhães Lemos E. P. E. - Porto.

\subsection{Instrumentos}

- Entrevista Clínica Estruturada para o Diagnóstico das Perturbações do Eixo I do DSM-IV (Structured Clinical Interview for DSM-IV Axis I Disorders, (SCID-I) (First et al., 1997), foi utilizada para estabelecer o diagnóstico. Recorreu-se à versão traduzida e adaptada ao Português por Maia, Pinto-Gouveia, Carvalho, Pimentel \& Guimarães (2006) in press.

- Inventário Depressivo de Beck (BDI), foi utilizado para a avaliação da sintomatologia depressiva (Beck, Steer, \& Garbin, 1988). O BDI é utilizado para avaliar a intensidade da depressão ao longo do tempo sobretudo em doentes deprimidos em tratamento (Barkham et al., 2008); para distinguir indivíduos deprimidos dos não-deprimidos em contextos psiquiátricos (Medina, Echeburúa, \& Aizpiri, 2007) e outros contextos médicos (Rowan et al., 2005); é igualmente usado para avaliação de sintomas depressivos em populações não clínicas, em estudantes (Gorenstein, Andrade, Zanolo, \& Artes, 2005; Lim et al., 2008; O'Connor, Berry, Weiss, \& Gilbert, 2002) ou na população geral (Appleton et al., 2008). O BDI é formado por 21 itens que procuram avaliar o estado depressivo nos seus aspectos afectivos, motivacionais, cognitivos e fisiológicos. O inventário utilizado é uma versão validada para a população portuguesa e mostra correlacionar-se de modo altamente significativo com o critério clínico de depressão (Vaz-Serra \& Pio-Abreu, 1973a; 1973b; 1973c). Neste estudo apresentou uma consistência interna boa a muito boa (Pestana \& Gageiro, 2003), com alfas de Cronbach de .88 na amostra de estudantes, .89 na amostra da população geral, e .95 na amostra de doentes. 
- Teste de Orientação para a Vida-Revista (LOT-R), o instrumento mede o grau de optimismo disposicional. Foi desenvolvido por Scheier e Carver (1985) e posteriormente revisto por Scheier, Carver e Bridges (1994). O LOT-R é constituído por 10 itens, dos quais 6 são indicadores de optimismo (itens 1, 3, 4, 7, 9 e 10). Os itens 3, 7 e 9 são cotados de forma inversa e os itens 2, 5, 6 e 8 não são cotados. Os sujeitos assinalam a sua opção de resposta de acordo com uma escala tipo Likert. Para cada item a cotação varia entre o e 4, sendo que a pontuação final da escala pode variar entre um mínimo de o e um máximo de 24 . Cotações mais elevadas nesta escala significam valores mais elevados de optimismo.

O LOT-R foi validado para a população portuguesa por Faria (2000) utilizando uma amostra constituída por alunos do ensino superior e população geral ( $N$ = 922). Na versão portuguesa o item 3 foi excluído ficando a ser considerados para o cálculo de optimismo os itens 1, 4, 7, 9 e 10. Assim, no que respeita à consistência interna, os resultados revelaram um coeficiente de alfa de Cronbach de .70 para o total da escala, indicando uma fiabilidade aceitável. A autora verificou que quanto à fidelidade teste-reteste, para um período de intervalo de 1 mês e meio, as correlações de Pearson eram de .55 , indicando estabilidade temporal razoável a curto prazo. A análise factorial, revelou uma estrutura unidimensional com um factor representando o optimismo e explicando $45.87 \%$ do total da variância (Faria, 2000). Neste estudo, a escala de optimismo apresentou uma consistência interna razoável (Pestana \& Gageiro, 2003) com alfas de Cronbach de .70 na amostra de estudantes, de .74 na amostra da população geral e de .72 na amostra de doentes. O baixo optimismo tem mostrado correlações negativas com patologia (Hirsch, Britton, \& Conner, 2009; Vickers \& Vogeltanz, 2000).

- Escala Multidimensional de Suporte Social Percebido (MSPSS), a escala faz a avaliação subjectiva de apoio social e foi desenhada para avaliar as percepções de adequação de apoio social a partir de fontes específicas: família, amigos e outras pessoas significativas. Trata-se de uma escala de auto-resposta tipo Likert, com 12 itens e 7 categorias de resposta (Zimet, Dahlem, Zimet, \& Farley, 1988). No estudo de validação da versão original da escala foram incluídos 275 estudantes universitários (136 mulheres e 139 sujeitos do género masculino). O estudo mostrou que a MSPSS possuía boa consistência interna (alfa de Cronbach de .88), a análise factorial mostrou uma solução com 3 factores (familia, amigos, outros significativos) moderadamente correlacionados. Quanto à estabilidade temporal, a escala revelou um teste-reteste de .85 . Tem sido utilizada num vasto número de estudos em contextos muito diversos, os resultados apontam para a existência de uma relação inversa significativa entre o suporte social e patologia em geral, bem como com estados psicopatológicos, particularmente de depressão e ansiedade (Brandt \& Weinert, 1981; Corna, Cairney, \& Streiner, 2010; Nunes, 2004; Sarason, Sarason, 
Potter, \& Antoni, 1985; Van Dorn, 2010). No presente trabalho foi utilizada a versão portuguesa da MSPSS de Carvalho, Pinto-Gouveia, Pimentel, Maia e Mota-Pereira, (submetido para publicação), sendo a consistência interna muito boa, com alfas de Cronbach do total da escala de .92 na amostra de estudantes, .94 na amostra da população geral e .90 na amostra de doentes.

- Escala de Derrota (ED) (Gilbert \& Allan, 1998), trata-se de um instrumento destinado a medir os sentimentos de derrota dos sujeitos. É uma escala tipo Likert com 16 itens e 5 categorias de resposta: $0=$ nunca, $1=$ raramente, $2=$ algumas vezes, 3 = frequentemente, 4 = sempre. Contém itens como "Sinto que me dei por vencido" ou "Sinto que perdi a minha posição na sociedade". A sua pontuação varia de o a 64 , significando que quanto mais elevada, mais intenso o sentimento de derrota.

\section{Procedimento}

Em todas as análises foi utilizado o programa SPSS versão 15.0. Foram consideradas diferenças estatisticamente significativas todos os valores com probabilidade associada inferior a .05 (Howell, 2006).

Procurámos seguir a metodologia dos autores para validação da escala, porém foram alterados alguns procedimentos e.g., utilizámos três amostras em vez de duas na validação original. Inicialmente procedeu-se a uma análise factorial com o objectivo de verificar a dimensionalidade da escala, tendo-se utilizado uma análise de componentes principais (Stevens, 1986; Spector, 1994; Tabachnick \& Fidell, 2007). Foram dois os critérios para extracção de um factor: valores próprios maiores que 1 antes de rotação (Kaiser, 1960) e utilização de um scree test (Cattel, 1966). Em todas as análises foi utilizada rotação oblíqua (Oblimin; delta = o), porém em todos os casos a rotação varimax replicou os resultados obtidos confirmando as soluções encontradas.

Procedeu-se de seguida à análise da consistência interna das escalas nas três amostras através do cálculo do alfa de Cronbach, considerada a melhor estimativa de fiabilidade de um teste (Nunnally \& Bernstein, 1994). A qualidade dos itens foi verificada através do cálculo da correlação do item com o total da escala excepto o próprio item (Nunnally \& Bernstein, 1994).

Seguidamente procedeu-se à avaliação da fidelidade teste-reteste, bem como da validade convergente e divergente, que foram analisadas através do coeficiente de correlação paramétrico de Pearson (Nunnally \& Bernstein, 1994). Foi estudada a estabilidade temporal das escalas num subgrupo da amostra de estudantes ( $n=$ 46) e noutro da população geral $(n=30)$, assim, o preenchimento do questionário foi repetido 3 semanas mais tarde. A exploração da validade convergente foi ana- 
lisada por meio de um estudo de correlação entre a escala de derrota e a medida de sintomatologia depressiva obtida com o BDI nas três amostras. A exploração da validade divergente foi analisada por meio de um estudo de correlação entre a escala de derrota com as medidas de optimismo e de suporte social.

Para avaliação da validade de construto, foi executada uma análise da variância (ANOVA) de modo a verificar se os doentes apresentavam pontuações superiores na $E D$, em relação aos sujeitos das outras duas amostras.

\section{RESULTADOS}

\subsection{Validade de conteúdo}

Adaptação da medida à língua portuguesa

Para a avaliação das características psicométricas da escala de derrota seguimos um processo semelhante ao de Gilbert \& Allan (1998). A ED procura apreender sentimentos de falhanço, insucesso e derrota, é composta por 16 itens e uma pontuação máxima possível de 64. Três dos itens são cotados inversamente: o item 2 (Sinto que sou uma pessoa de sucesso), o item 4 (Sinto que sou um(a) vencedor(a)) e o item 9 (Sinto-me capaz de lidar com o que quer que seja que a vida me apresente);

A adaptação da Escala de Derrota envolveu a tradução, retroversão e comparação posterior com a versão original para verificação das possiveis diferenças e retradução final. Neste passo teve-se em atenção sobretudo o conteúdo dos itens. Através de discussões entre especialistas do tema em estudo e com colaboração de peritos nas línguas portuguesa e inglesa, verificou-se se o conteúdo dos itens da versão resultante da tradução tinha o sentido proposto pelos originais, tendo o grupo de especialistas concluido pela manutenção do número de itens. Após este passo administraram-se as escalas de auto-avaliação a uma amostra de 25 estudantes do ensino superior. Foi-Ihe explicado quais os objectivos solicitando-Ihe que apontassem, após terem respondido às escalas, dificuldades, dúvidas, críticas ou comentários que entendessem relevantes. Devido à adequada compreensão dos itens não resultaram modificações na escala.

\section{Estatistica descritiva}

As médias e desvios padrão para todos os valores das escalas nas três amostras são apresentados na Tabela 1. Para verificar um possível efeito de género, explorámos nas três amostras a existência de diferenças nas médias dos quatro instrumentos 
por meio de testes-t. Verificou-se que no grupo da população geral e no grupo de doentes não existiam diferenças entre os valores das quatro escalas nos dois géneros. No grupo de estudantes não existia diferença significativa no valor da Escala de Derrota, porém no BDI, na MSPSS e no LOT-R existiam diferenças significativas. No género feminino as classificações foram mais elevadas no BDI $[t(512.868)=3.573, p=.000, M=7.59$ versus $M=5.78]$ e na MSPSS $[t(152.378)=$ $4.575 P=000 . M=72.87$ versus $M=66.29]$; ao contrário, o género masculino teve maior classificação no LOT-R $[t(291.844)=3.571, p=000, M=14.26$ versus $M=13.27]$.

\subsection{Dimensionalidade}

\subsubsection{Estrutura factorial da Escala de Derrota}

$\mathrm{Na}$ amostra de estudantes, o Coeficiente de Kaiser-Meier-Olkin de .939 e o valor do Teste de Esfericidade de Bartlett de $x^{2}(120)=5718,167, p=.000$, permitem-nos concluir pela adequação da amostra e da sua matriz de correlações para seguir a análise factorial. Foram obtidos dois factores, tal como na versão original, explicando $60.52 \%$ da variância total da escala. Todos os itens tiveram saturações acima de .58 pelo menos num dos dois factores. O primeiro factor explicava $48.93 \%$ da variância total. O segundo factor explicava $11.59 \%$ da variância e incluía o grupo de 3 itens que são codificados de modo inverso (itens 2, 4 e 9) descritos atrás. A correlação dos dois factores foi de .54 .

Seguindo ainda o procedimento dos autores na versão original, ao forçar um só factor foram obtidas saturações nos três itens referidos muito próximos dos valores mínimos de saturação recomendáveis de .30 (Tinsley \& Tinsley, 1987). Porém, os restantes itens saturaram entre .57 e .81 e resultando uma variância total de $48.93 \%$, Tabela 2.

$\mathrm{Na}$ amostra da população geral, o coeficiente de Kaiser-Meier-Olkin obtido de .927 e o valor para o Teste de Esfericidade de Bartlett de $x^{2}(120)=3445.701, p$ = .000, permitem-nos concluir pela adequação da amostra e da sua matriz de correlações para prosseguir a análise factorial. O resultado foi em tudo idêntico ao obtido no grupo de estudantes, foram obtidos dois factores explicando $57.65 \%$ da variância total. Todos os itens tiveram pontuações acima de .57 pelo menos num dos dois factores. O primeiro factor explicava $45.27 \%$ e segundo factor explicava $12.38 \%$ da variância total, a distribuição dos itens foi igual à obtida no grupo de estudantes. Ao forçar um só factor foram obtidas saturações entre .57 e .84 com excepção dos três itens referidos (itens 4, 2 e 9) abaixo dos valores mínimos de saturação desejáveis (Tinsley \& Tinsley, 1987), resultando uma variância total de $45.27 \%$, Tabela 2 . 
Na amostra de doentes, o coeficiente de Kaiser-Meier-Olkin obtido de . 909 e o valor de $x^{2}(120)=1010.981, p=.000$ para o Teste de Esfericidade de Bartlett, permitem-nos concluir pela adequação da amostra e da matriz de correlações para continuar análise factorial. A análise de componentes principais produziu uma solução com três factores explicando $64.40 \%$ da variância total. Todos os 16 itens saturaram acima de .48 pelo menos num dos factores. Porém ao contrário da amostra de estudantes e da população geral esta estrutura factorial não era facilmente interpretável. O factor 1 explicava $49.19 \%$ da variância e era composto por cinco itens relacionados com sentimentos de falhanço e incapacidade para lutar mais, curiosamente itens seguidos na estrutura facial da escala (itens 12, $13,14,15$ e 16) sem outro motivo aparente para associação. O factor 2 explicava $8.26 \%$ e era composto pelos itens 1, 3, 5, 6, 7 e 8 sem aparente independência lógica, sobressaindo como mais saturado (.71) o item 7 relacionado com sentimento de impotência perante a vida. O factor 3 explicava $6.96 \%$ da variância e era composto pelo grupo itens referidos que são cotados de modo inverso, itens 2, 4 e 9, mais os itens 10 e 11, "Sinto que bati no fundo" e "Sinto-me completamente fora de acção" respectivamente. O scree test (Cattel, 1966) sugeriu uma solução de um ou dois factores. Forçando uma solução com dois factores não se obteve ainda uma estrutura facilmente interpretável, sendo o factor 2 composto pelos itens do factor 3 das soluções anteriores verificadas na amostra de estudantes e da população geral e explicando somente $8.26 \%$ da variância. Optou-se por explorar uma solução unifactorial que explicava $49.19 \%$ da variância, com todos os itens a saturar entre .55 e .89 com excepção do item 9 com um valor de saturação de .33 .

Apesar do comportamento dos itens já referidos: 2, 4 e 9, a revelarem saturações baixas nalguns cálculos i.e., inferiores a .30, optámos por não os eliminar, um dos motivos foi o facto dos outros itens saturarem, entre .55 e .89 (Tabachnick \& Fidell, 2007; Tinsley \& Tinsley, 1987). Atribuímos o resultado ao facto desses itens estarem na ordem inversa. Na análise factorial, quando há variáveis com baixas saturações, não se controla a sua influência eliminando-as pura e simplesmente e utilizando somente variáveis com saturações elevadas. Cabe ao investigador excluí-las ou não, de acordo com o fundamento teórico subjacente (Pestana \& Gageiro, 2003). Por outro lado, a extracção de soluções factoriais com variâncias totais entre $40 \%$ a $50 \%$ reflectem grandeza adequada das informações recolhidas pelo instrumento de auto-resposta (Gorsuch, 1983). Os valores da variância obtidos na versão portuguesa da ED foram superiores a $45 \%$, portanto dentro desse intervalo. Ponderando os resultados nos três grupos e utilizando uma abordagem conservadora da escala pensamos poder aceitar como os seus autores uma solução unidimensional (Gilbert \& Allan, 1998). Os itens, os eigenvalues, a saturação dos factores bem como a variância em cada amostra estão representados na Tabela 2. 


\subsubsection{Análise dos itens e consistência interna}

As correlações médias item-item estiveram no intervalo de 36 a .44. É melhor que as correlações inter-item sejam baixas a moderadas. É necessária cautela na avaliação destas correlações, se forem tendencialmente baixas ou negativas significa que existe uma falta de coerência na escala. Por outro lado se forem tendencialmente elevadas pode indicar redundância nos itens i.e., se um item apresenta uma correlação muito elevada com outro, possivelmente não é necessário (Miles \& Gilbert, 2005).

O alfa de Cronbach para a Escala de Derrota no grupo de estudantes foi de .92 (.91 para o género feminino e .93 para o género masculino); no grupo da população geral foi de .90 (.89 para o género feminino e .91 para o género masculino) e no grupo de doentes foi de .93 (.93 para o género feminino e .93 para o género masculino). Estes resultados sugerem que a ED tem valores de consistência interna muito bons para as três amostras, Tabela 3.

$\mathrm{Na}$ amostra de estudantes, ao analisarmos as correlações item-total corrigido da ED verificamos que apresentam valores elevados em geral (de .51 a .78) com excepção dos itens, 2, 4, e 9 com uma correlação item-total corrigida de .33, .34 e .26. Nenhum item se eliminado afecta o alfa de Cronbach com excepção dos itens 2, 4 e 9 que elevam o alfa de Cronbach em uma décima no caso dos dois primeiros, e quatro décimas no caso do último.

Na amostra da população geral ao analisar-mos as correlações item-total corrigido da ED verificamos que apresentam valores moderados a elevados em geral (de 47 a .75) com excepção dos itens, 2, 4, e 9 que apresentam uma correlação item-total corrigida de .11, .22 e .14, neste caso nenhum item se eliminado afecta o alfa de Cronbach inclusive os itens 2,4 e 9 .

$\mathrm{Na}$ amostra de doentes ao analisarmos as correlações item-total corrigido da ED verificamos que apresentam valores elevados em geral (de .50 a .85) com excepção do item 9 com uma correlação item-total corrigida de .30. Nenhum item se eliminado afecta o alfa de Cronbach o que nos indica não ser necessário excluir nenhum item (Nunnally \& Bernstein, 1994; Tinsley \& Tinsley, 1987), Tabela 3.

\subsubsection{Fidelidade teste-reteste}

Num subgrupo da amostra de estudantes $(n=46)$ e noutro da população geral $(n=30)$ foi repetido o preenchimento dos questionários 3 semanas mais tarde. $O$ resultado do estudo da estabilidade temporal das escalas demonstrou resultados moderados a altos (Pestana \& Gageiro, 2003), com coeficientes de correlação de Pearson de .68 no grupo de estudantes e de .83 no grupo da população geral. Ao nível 
da consistência interna, a ED apresentou um valor de alfa de Cronbach para o reteste de .95 e .86 respectivamente, para a amostra de estudantes e da população geral.

\subsubsection{Validade convergente}

Para avaliar a validade externa ou de critério da ED nas três amostras foi utilizado o BDI. Procedeu-se a um estudo de correlação entre a ED e o BDI na amostra de estudantes, da população geral e de doentes, tendo sido obtidas correlações moderadas, respectivamente: $.45, .66$ e .68 para um nível de significância de $p<$ .001. Esse facto aponta para a existência de uma convergência, mais do que uma divergência entre ambas, Tabela 4.

\subsubsection{Validade divergente}

Para avaliar a validade divergente nas três amostras foram utilizadas duas escalas cujos construtos, o suporte social percebido e o optimismo disposicional, se deveriam correlacionar negativamente com o construto de derrota. Para isso utilizou-se a Escala Multidimensional de Suporte Social Percebido e o Teste de Orientação para a Vida (ou escala de optimismo). Procedeu-se a um estudo de correlação entre a Escala de Derrota e as duas escalas referidas nas três amostras, obtendo-se correlações negativas e significativas entre -.26 e -.56. Estes resultados revelaram a existência de correlações baixas a moderadas (Cohen, 1988; Pestana \& Gageiro, 2003) entre a MSPSS e o LOT-R e os valores da ED nas três amostras. Esse facto aponta para a existência de uma divergência, entre o construto de derrota por um lado e os construtos de suporte social percebido e optimismo por outro, Tabela 5.

\subsubsection{Validade de construto}

A validade de construto é a validade nobre de qualquer teste. É ela que garante que o teste mede o que se propõe medir. Para validar a ED inspeccionámos a sua distribuição nas três amostras, sendo assim, as pontuações deveriam ser superiores na amostra de doentes em relação às amostras de estudantes e da população geral. Foi realizada uma análise da variância (ANOVA) no sentido de verificar se havia diferenças nas médias da ED estatisticamente significativas nas três amostras. Caso houvesse, deveria avaliar-se entre que grupos se apresentavam essas diferenças, pelo que realizámos um teste de Tukey para localização das diferenças.

Verificou-se que havia diferenças significativas entre os três grupos, Tabela 5. Os doentes tinham valores mais elevados do que os estudantes e que a população geral. Por outro lado, os estudantes tinham pontuações mais elevadas do que a população geral não atingindo porém, marginalmente, significado estatístico ( $p=.058$ ). 


\section{DISCUSSÃO}

Esta investigação procurou contribuir para a validação da versão portuguesa da Escala de Derrota bem como para o estudo das suas características psicométricas, especificamente da estrutura factorial, consistência interna, estabilidade temporal, validade convergente, divergente e de construto em três amostras, uma de estudantes, uma da população geral e uma de doentes com depressão major.

Quanto à validade de construto da ED, foram utilizados procedimentos estatísticos que permitissem compreender a organização dos itens que compõem a medida, através de um método estatístico multivariado de cariz exploratório.

Quanto à ocorrência de dois factores na ED nas três amostras, devemos realçar por um lado o facto de serem itens cotados inversamente, por outro a particular a natureza dos itens: "Sinto que sou uma pessoa de sucesso" (item 2) "Sinto que sou um(a) vencedor(a)" (item 4) "Sinto-me capaz de lidar com o que quer que seja que a vida me apresente" (Item 9). Quanto à natureza dos itens, os autores não o referem, mas talvez pudesse considerar-se que o conteúdo destes três itens aborda o tema do sucesso, vitória e coragem e que não é exactamente o mesmo, cotar os itens inversamente e, esperar que o mesmo ocorra com o seu significado. Inverter o significado seria por exemplo colocá-los na negativa e.g., "Não sinto que sou uma pessoa de sucesso". De qualquer modo pensamos que numa abordagem conservadora da escala poder aceitar como os seus autores uma solução unidimensional. Considerando o comportamento nas três amostras, apesar de existirem itens com baixas saturações, não se controla a sua influência eliminando-os simplesmente e utilizando somente variáveis com saturações mais elevadas. Apesar destes dados parece prematuro caracterizar estes factores como subescalas diferentes nestas amostras. A correlação entre os dois factores obtida na amostra de doentes foi de $r=.52$ o que é suficientemente forte para considerar que é possível substituir os dois por um só factor (Nunnally \& Bernstein, 1994), esse facto já não é tão defensável na amostra de estudantes com $r=.23$ e na amostra da população geral $r=.04$.

No presente estudo, foi encontrado um alfa de Cronbach elevado para o total da $E D$, indicador de excelente consistência interna da escala. Este resultado está de acordo com o que foi reportado no estudo original da escala por Gilbert e Allan (1998), que encontraram indicadores de fidelidade elevados para o total da escala.

Parece-nos que uma solução unifactorial está mais de acordo com o fundamento teórico subjacente i.e., o aspecto central da derrota, do insucesso, da impotência, da perda de confiança e perda de posto social. Caso se repliquem estes resultados e se confirmem em estudos prospectivos, consideraremos testar modificações ligeiras na estrutura destes três itens. 
Na nossa amostra, a ED apresentou bons índices de fidelidade teste-reteste, mostrando uma boa estabilidade temporal para um intervalo de três semanas.

Em relação à validade convergente, na nossa investigação foi encontrado um coeficiente de correlação elevado e estatisticamente significativo com o BDI como medida da sintomatologia depressiva nas três amostras. Este resultado aponta pois para uma boa validade convergente da ED e suporta os dados encontrados noutros estudos, nos quais a derrota aparece positivamente associada a sintomatologia depressiva e outra psicopatologia. Para além do BDI foram utilizadas outros instrumentos e.g., Hopelessness Scale, Depressive Experiences Questionnaire, Fawcett-Clark Pleasure Capacity Scale, Mood and Anxiety Symptoms Questionnaire ou a Snaith-Hamilton Pleasure Scale.

O suporte social (Brandt \& Weinert, 1981; Corna, Cairney, \& Streiner, 2010; Nunes, 2004; Sarason et al., 1985; Van Dorn, 2010) e o optimismo disposicional (Hardin, \& Leong, 2005; Hirsch, Britton, \& Conner, 2009; Vickers \& Vogeltanz, 2000) têm demonstrado correlacionar-se negativamente com psicopatologia.

A validade divergente ficou assim definida com instrumentos que avaliam construtos que deveriam associar-se negativamente com a derrota e.g., o suporte social e o optimismo. A probabilidade de ficar em estado de derrota na luta pela vida deve depender em grande medida da percepção de suporte social. Ter aliados é uma receita para o sucesso e para a vitória. Do mesmo modo, o optimismo disposicional já demonstrou correlacionar-se negativamente com psicopatologia, e em particular depressão, pelo que seria de esperar que o mesmo ocorresse com a derrota.

No homem a vivência de derrota parece ser fundamental na diminuição da actividade dos sistemas de reforço e da ocorrência e manutenção do afecto depressivo e anedonia. A adopção da derrota patológica (intensidade excessiva, início prematuro e duração prolongada) no ser humano pode ser atribuída a história de punição excessiva e autoritarismo parental, de violência física ou abuso sexual (Sloman \& Gilbert, 2000). Na depressão recorrente em geral e na depressão crónica em particular (Andrews, 1998), é frequente terem ocorrido experiências adversas na infância e.g., violência psicológica, física e abuso sexual que perturbam o desenvolvimento e o funcionamento psicobiológico a longo prazo (Hart, Gunnar, \& Cicchetti, 1996; Rosemblum et al., 1994; Bifulco et al., 2005).

Cada vez é mais frequente nas sociedades contemporâneas a existência de circunstâncias de derrota e.g., ambientes aversivos, de pobreza, hostis, onde a pessoa é sujeita a conflitos, dominada, oprimida e humilhada levando a perda de estatuto social e à emissão comportamentos de submissão, bem como ao desenvolvimento de estratégias de comparação social negativa. Estes factos apontam 
para a necessidade de mais investigação acerca do papel da derrota na génese de psicopatologia, particularmente depressiva.

\section{Limitações e investigações futuras}

Os nossos resultados devem ser considerados tendo em conta algumas limitações metodológicas. Em primeiro lugar tratou-se de um estudo transversal, pelo que a avaliação do dinamismo da ED não pôde ser efectuado.Em segundo lugar, a dimensão da amostra de doentes esteve no limite do aceitável para estudos de análise factorial. Por último, utilizámos metodologia pouco ampla para avaliação da validade convergente, no futuro sugere-se alargar a avaliação a outras medidas de vulnerabilidade emocional e stress; por outro lado, parecenos necessário ampliar a aplicação da ED em contextos clínicos particularmente em estudos longitudinais.

\section{CONCLUSÕES}

A Escala de Derrota agora apresentada torna possível a avaliação do sentimento de derrota; manifesta sinais de alta consistência interna, parecendo favorecer uma estrutura unidimensional. A versão portuguesa mostra-se associada positivamente a sintomatologia depressiva e negativamente ao suporte social e optimismo. As características psicométricas obtidas neste estudo, replicam em geral os resultados obtidos pelos seus autores em amostras britânicas. Globalmente, a ED demonstrou ter características psicométricas adequadas para poder utilizar-se na população portuguesa em contextos clínicos e não clínicos.

\section{Referências bibliográficas}

Adams, N., \& Boice, R. (1983). A longitudinal study of dominance in an outdoor colony of domestic rats. Journal of Comparative Psychology. 97, 24-33.

Allan, S., \& Gilbert, P. (1995). A Social Comparison Scale: psychometric properties and relationship to psychopathology. Personality Individual Differences, 19, 293-299.

Allan, S., \& Gilbert, P. (1997). Submissive behaviour and psychopathology. British Journal of Clinical Psychology, 36, 467-488.

Andrews, B. (1998). Shame and childhood sexual abuse. In Gilbert, P., Andrews, B. (Eds), Shame: Interpersonal Behavior, Psychopathology and Culture (pp.176-19o). New York: Oxford University Press. 
Appleton, K., Gunnell, D., Peters, T. J., Ness, A. R., Kessler, D., \& Rogers, P. J. (2008). No clear evidence of an association between plasma concentrations of $n-3$ long-chain polyunsaturated fatty acids and depressed mood in a non-clinical population. Prostaglandins, Leukotrienes and Essential Fatty Acids, 78, 337-342.

Bao, A. M., Meinen, G., \& Swaab, D. F. (2008). The stress system in depression and neurodegeneration: focus on the human hypothalamus. Brain Research Reviews, 57(2), 531-53.

Barkham, M., Stiles, W., Connell, J., Twigg, E., Leach, C., Lucock, M., ... Angus, L. (2008). Effects of psychological therapies in randomized trials and practice-based studies. British Journal of Clinical Psychology, 47, 397-415.

Beck, A., Steer, R., \& Garbin, M. (1988). Psychometric properties of the Beck Depression Inventory: twenty-five years of evaluation. Clinical Psychology Review, 8, 77-100.

Bifulco, A., Bernazzani, A., Moran, P. M., \& Jacobs, C. (2005). The childhood experience of care and abuse questionnaire (CECA.O) - validation in a community series. British Journal of Clinical Psychology, 44, 563-581.

Blanchard, D. C., \& Blanchard, R. J. (1990). Behavioral correlates of chronic dominancesubordination relationships of male rats in a seminatural situation. Neuroscience and Biobehavioral Review, 14, 455-462.

Brandt, P. A., \& Weinert, C. (1981). The PRO - A social support measure. Nursing Research, 30 , 277-280.

Carobrez, S. G., Gasparotto, O. C., Buwalda, B., \& Bohus, B. (2002). Long-term consequences of social stress on corticosterone and IL-1beta levels in endotoxin-challenged rats. Physiology and Behavior, 76(1), 99-105.

Carvalho, Pinto-Gouveia, Pimentel, Maia, Gilbert, \& Mota-Pereira, Entrapment and defeat perceptions in depressive symptomatology: Through an evolutionary approach (submetido para publicação)

Carvalho, S., Pinto-Gouveia, J., Pimentel, P., \& Maia, D. (2007). Mediation of depression by entrapment perception: through an evolutionary exploration (Book of Abstracts). World Congress of Behavioural and Cognitive Therapies, Barcelona.

Carvalho, S., Pinto-Gouveia, J., Pimentel, P., Maia, D., \& Mota-Pereira, J. (2010). Características psicométricas da versão portuguesa da Escala Multidimensional de Suporte Social Percebido (The Multidimensional Scale of Perceived Social Support - MSPSS) (submetido para publicação).

Cattel, R. B. (1966). The scree test for the number of factors. Multivariate Behavioral Research, 22, 44-50.

Chuang, J. C., Cui, H., Mason, B. L., Mahgoub, M., Bookout, A. L., Yu, H. G., Perello, M., Elmquist, J. K., Repa, J. J., Zigman, J. M., Lutter, M. (2010). Chronic social defeat stress disrupts regulation of lipid synthesis. Journal of Lipid Research, 51(6), 1344-53.

Cohen, J. (1988). Statistical power analysis for the behavioral sciences (2nd ed.). Hillsdale NJ: Erlbaum.

Corna, L. M., Cairney, J., \& Streiner, D. L. (2010). Suicide Ideation in Older Adults: Relationship to Mental Health Problems and Service Use. The Gerontologist, doi: 10.1093/ geront/gnqo48

Faria, M.C. (2000). Comunicação e Bem-Estar no Limiar Do Século XXI, Conhecer Através da Relação e Orientar para a Saúde. Tese de doutoramento em Psicologia, na área de especialização em Psicologia da Saúde, apresentada à Faculdade de Psicologia e de Ciências da Educação da Universidade de Coimbra (Não publicada). 
First, M. B., Spitzer, R. L., Gibbon M., \& Williams, J. B. W. Structured Clinical Interview for DSMIV Axis I Disorders, Clinician Version (SCID-CV) (1996). Washington, D.C.: American Psychiatric Press, Inc.

Frischknecht, H. R., Siegfried, B., \& Waser, P.G. (1982). Learning of submissive behaviour in mice: a new model. Behavioural Processes, 7, 235-245.

484 Gilbert, P. (1984). Depression: From Psychology to Brain State. London: Lawrence Erlbaum Associates. Gilbert, P. (1989). Human Nature and Suffering. Hove: Lawrence Erlbaum.

Gilbert, P. (1992). Depression: The Evolution of Powerlessness. Hove: Lawrence Erlbaum and New York: Guilford Press.

Gilbert, P. (2000). The relationship of shame, social anxiety and depression: The role of the evaluation of social rank. Clinical Psychology and Psychotherapy, 7, 174-189.

Gilbert, P. (2001). Depression and stress: A biopsychosocial exploration of evolved functions and mechanisms. Stress: The International Journal of the Biology of Stress, 4, 121-135.

Gilbert, P., \& Allan, S. (1994). Assertiveness, submissive behaviour and social comparison. British Journal of Clinical Psychology, 33, 295-306.

Gilbert, P., \& Allan, S. (1998). The role of defeat and entrapment (arrested flight) in depression: an exploration of an evolutionary view. Psychological Medicine, 28, 584-597.

Gilbert, P., Allan, S., Brough, S., Melley, S., \& Miles, J. N. (2002). Relationship of anhedonia and anxiety to social rank, defeat and entrapment. Journal of Affective Disorders, 71, 141-51.

Gilbert, P., \& Gilbert, J. (2003). Entrapment and arrested fight and flight in depression: An exploration using focus groups. Psychology and Psychotherapy: Theory Research and Practice, $76,173-188$.

Gilbert, P., Gilbert, J., \& Irons, C. (2004). Life events, entrapments and arrested anger in depression. Journal of Affective Disorders, 79, 149-160.

Gorenstein, C., Andrade, L., Zanolo, E., \& Artes, R. (2005). Expression of depressive symptoms in a nonclinical Brazilian adolescent sample. Canadian Journal of Psychiatry, 50, 129-36.

Gorsuch, R. L. (1983). Factor analysis. Hillsdale, NJ: Erlbaum.

Griffiths, J., Ravindran, A. V., Merali, Z., \& Anisman, H. (2000). Dysthymia: a review of pharmacological and behavioral factors. Molecular Psychiatry, 5, 242-61.

Hardin, E. E., \& Leong, F. T. L. (2005). Optimism and Pessimism as Mediators of the Relations Between Self-Discrepancies and Distress Among Asian and European Americans. Journal of Counseling Psychology, 52(1), 25-35, doi: 10.1037/0022-0167.52.1.25.

Hart, J., Gunnar, M., \& Cicchetti, D. (1996). Altered neuroendocrine activity in maltreated children related to symptoms of depression. Development and Psychopathology, 8, 201-214.

Henry, J. (1982). The relation of social to biological process in disease. Social Science Medicine, 16, 369-390.

Hirsch, J. K., Britton, P. C., \& Conner, K. R., (2009). Psychometric Evaluation of the Life Orientation Test-Revised in Treated Opiate Dependent Individuals. International Journal of Mental Health and Addiction, doi: 10.1007/s11469-009-9224-2.

Howell, D. (2006). Statistical methods for psychology ( $6^{\text {th }}$ ed.). USA: Thomson Wadsworth.

Kaiser, H. F. (1960). The application of electronic computers to factor analysis. Educational and Psychological Measurement, 20, 141-151.

Kemeny, M. (2009). Psychobiological responses to social threat: evolution of a psychological model in psychoneuroimmunology. Brain, Behavior and Immunity. 23(1), 1-9. 
Lagerspetz, K. M. J., \& Sandnabba, K. (1982). The decline of aggressiveness in male mice during group caging as determined by punishment delivered by the cage mates. Aggressive Behavior, 8, 319-328.

Levitan, R. D., Vaccarino, F. J., Brown, G. M., \& Kennedy, S. H. (2002). Low-dose dexamethasone challenge in women with atypical major depression: pilot study. Journal of psychiatry and neuroscience, 27(1), 47-51.

Levitan, R., Hasey, G. \& Sloman, L. (2000). Major depression and the involuntary defeat strategy; biological correlates. In L. Sloman and P. Gilbert (Ed.), Subordination and Defeat: An Evolutionary Approach to Mood Disorders and Their Therapy (pp. 95-114). Lawrence Erlbaum: Mahwah, N. J.

Lim, J. S., Kim, S. J., Jeon, W. T., Cha, K. R., Park, J. H., \& Kim, C. H. (2008). Reliability and validity of the Korean version of Obsessive-Compulsive Inventory-Revised in a non-clinical sample. Yonsei Medical Journal, 49, 909-16.

Martin, Y., Gilbert, P., McEwan, K., \& Irons, C. (2006). The relation of entrapment, shame and guilt to depression, in carers of people with dementia. Aging and Mental Health, 10, 101-6.

McQuade R., \& Young A. H. (2000). Future therapeutic targets in mood disorders: the glucocorticoid receptor. British Journal of Psychiatry, 177, 390-5.

Medina, B., Echeburúa, E., \& Aizpiri, J. (2007). Psychopathological symptoms and personality traits in alcohol-dependent patients: a comparative study. Adicciones, 19, 373-81.

Meerlo, P., de Boer, S.F., Koolhaas, J. M., Daan, S., \& Van den Hoofdakker, R. H. (1996). Changes in daily rhythms of body temperature and activity after a single social defeat in rats. Physiology and Behavior, 59, 735-739.

Miles, J., \& Gilbert, P. (2005). A Handbook of Research Methods in Clinical and Health Psychology. London: Oxford University Press.

Nemeroff, C. (1998). Psychopharmacology of affective disorders in the 21st century. Biological Psychiatry, 44, 517-525.

Nunes, M. (2004). Qualidade de Vida e Diabetes: Variáveis Psicossociais (Doctoral dissertation). Universidade de Extremadura: Espanha.

Nunnally, J., \& Bernstein, I. H. (1994). Psychometric theory (3 ${ }^{\text {rd }}$ ed.). New York: McGraw-Hill.

O'Connor, L. E., Berry, J. W., Weiss, J., \& Gilbert, P. (2002). Guilt, submission and empathy in depression. Journal of Affective Disorders, 71, 19-27.

Pestana, M., \& Gageiro, J. N. (2003). Análise de dados para ciências sociais. A complementaridade do SPSS ( $3^{\mathrm{a}}$ ed). Edições Sílabo, Lisboa.

Pinto-Gouveia, J. (2000). Ansiedade Social: da timidez à fobia social. Coimbra, Quarteto.

Price, J. S., Sloman, L., Gardner, R., Gilbert, P., \& Rohde, P. (1994). The social competition hypothesis of depression. British Journal of Psychiatry, 164, 309-135.

Price, J. S. \& Sloman, L. (1987). Depression as yielding behavior: an animal model based on Schjelderup-Ebbe's pecking order. Ethology and Sociobiology, 8, 855-985.

Price, J. S. (1969). The ritualisation of agonistic behaviour as a determinant of variation along the neuroticism/stability dimension of personality. Proceedings of the Royal Society of Medicine, 62, 1107-1111.

Price, J. S. (1972). Genetic and phylogenetic aspects of mood variation. International Journal of Mental Health, 1, 124-144.

Raab, A., Dantzer, R., Michaud, B., Mormede, P., Taghzouti, K., Simon, H., \& LeMoal, M., (1986). Behavioural, physiological and immunological consequences of social status and aggression in chronically co-existing resident-intruder dyads of male rats. Physiology and Behavior, 36, 223-228. 
Raadsheer, F. C., Hoogendijk, W. J., Stam, F. C., Tilders, F. J., \& Swaab, D. F. (1994). Increased numbers of corticotropin-releasing hormone expressing neurons in the hypothalamic paraventricular nucleus of depressed patients. Neuroendocrinology, 6o(4), 436-44.

Rasmussen, S., Fraser, L., Gotz, M., MacHale, S., Mackie, R., Masterton, G., McConachie, S., \& O'Connor, R.C. (2010). Elaborating the Cry of Pain model of suicidality: Testing a psychological model in a sample of first-time and repeat self-harm patients. British Journal of Clinical Psychology, 49, 15-30.

Rosenblum, L., Coplan, J., Friedman, S., Bassoff, T., Gorman, J.M., \& Andrews, M.W. (1994). Adverse early experiences affect noradrenergic and serotonergic functioning in adult primates. Biological Psychiatry, 35, 221-227.

Rowan, P. J., Al-Jurdi, R., Tavakoli-Tabasi, S., Kunik, M. E., Satrom, S. L., \& El-Serag, H. B. (2005). Physical and psychosocial contributors to quality of life in veterans with hepatitis C not on antiviral therapy. Journal of Clinical Gastroenterology, 39, 731-6.

Sapolsky, R. M. (2000). The possibility of neurotoxicity in the hippocampus in major depression: a primer on neuron death. Biological Psychiatry, 15(48), 755-65.

Sapolsky, R. M. (2003). Stress and Plasticity in the Limbic System. Neurochemical Research, 28(1), 1735-1742.

Sarason, I. G., Sarason, B. R., Potter, E. H., \& Antoni, M. H. (1985). Life events, social support, and illness. Psychosomatic Medicine, 47, 156-163.

Scheier, M. F., \& Carver, C. S. (1985). Optimism, coping, and health: Assessment and implications of generalized outcome expectancies. Health Psychology, 4, 219-247.

Scheier, M. F., Carver, C. S., \& Bridges, M. W. (1994). Distinguishing optimism from neuroticism (and trait anxiety, self-mastery, and self-esteem): A reevaluation of the Life Orientation Test. Journal of Personality and Social Psychology, 67, 1063-1078.

Shahmanesh, M., Wayal, S., Cowan, F., Mabey, D., Copas, A., \& Patel, V. (2009). Suicidal behavior among female sex workers in Goa, India: the silent epidemic. American Journal of Public Health, 99, 1239-46.

Sloman, L., \& Gilbert, P. (2000). Subordination and Defeat An Evolutionary Approach To Mood Disorders and Their Therapy. Ed Routledge, USA.

Spector, P. E. (1994). Summated rating scale construction: an introduction. In Lewis-Beck (Ed). Basic Measurement (pp 229-300). Sage: London.

Stevens, J. (1986). Applied multivariate statistics for the social sciences. New Jersey: Hillsdale.

Sturman, E. D., \& Mongrain, M. (2005). Self-criticism and major depression: an evolutionary perspective. British Journal of Clinical Psychology, 44, 505-19.

Tabachnick, B., \& Fidell, L. (2007). Using Multivariate Statistics. New York: Pearson Education.

Taylor, P. J., Gooding, P. A., Wood, A. M., Johnson, J. Pratt, D., \& Tarrier, N. (2010) Defeat and entrapment in schizophrenia: The relationship with suicidal ideation and positive psychotic symptoms. Psychiatry Research, 178, 244-248.

Tinsley, H. E., \& Tinsley, D. J. (1987). Uses of factor analysis in counseling psychology research. Journal of Counseling Psychology, 34(4), 414-424.

Troop, N. A., \& Baker, A. H. (2008). The specificity of social rank in eating disorder versus depressive symptoms. Eating Disorders, 16, 331-41.

Van de Poll, N. E., Smeets, J., Van Oyen, H. G., \& Van der Zwan, S. M. (1982). Behavioural consequences of agonistic experiences in rats: sex differences and effects of testosterone. Journal of Comparative and Physiological Psychology, 96, 893-903. 
Van Dorn, R. A, Kosterman, R., Williams, J. H., Chandler, K., Young, M., Catalano, R. F., \& Hawkins, J. (2010). The Relationship Between Outpatient Mental Health Treatment and Subsequent Mental Health Symptoms and Disorders in Young Adults. Administration and Policy in Mental Health, doi:10.1007/s10488-010-0291-2.

Vaz-Serra, A. S., \& Pio-Abreu, J. L. (1973a). Aferição dos quadros clínicos depressivos. I-Ensaio de aplicação do "Inventário Depressivo de Beck" a uma amostra portuguesa de doentes deprimidos. Coimbra Médica, 20, 623-644.

Vaz-Serra, A. S., \& Pio-Abreu, J. L. (1973b). Aferição dos quadros clínicos depressivos. Il-Estudo preliminar de novos agrupamentos sintomatológicos para complemento do "Inventário Depressivo de Beck". Coimbra Médica, 20, 713-736.

Vaz-Serra, A. S., \& Pio-Abreu, J. L. (1973C). Análise factorial das depressões: emergência de factores numa amostra portuguesa de doentes deprimidos. Coimbra Médica, 20, 875-892.

Vickers K. S., \& Vogeltanz, N. D. (2000). Dispositional optimism as a predictor of depressive symptoms over time. Personality and Individual Differences, 28, 259-272.

Von Holst, D. (1986). Vegetative and somatic components of tree shrews behaviour. Journal of the Autonomic Nervous System, Suppl., 657-670.

Williams, J. (2001). Suicide and attempted suicide: understanding the cry of pain ( $2^{\text {nd }}$ ed.). London: Penguin Books.

Williams, J.L., \& Lierle, D. M., 1988. Effects of repeated defeat by a dominant conspecific on subsequent pain sensitivity, open-field activity and escape learning. Animal Learning and Behavior, 16, 477-485.

Wilner, P., \& Goldstein, R. (2001). Mediation of depression by perceptions of defeat and entrapment in high-stress mothers. British Journal of Medical Psychology, 74, 473-485.

Zimet, G. D. (1998). The Multidimensional Scale of Perceived Social Support (MSPSS) Journal of Personality Assessment, 52, 30-41.

\section{Defeat - concept and assessment: Psychometric properties of the Portu- guese version of the Defeat Scale}

The social rank theory, in the perspective of evolutionary psychopathology, suggests that defeat is an adaptive psychobiological response especially in agonistic conflicting situations. Animal and human studies showed the neurobiological negative impact of defeat situations. In human being, the defeat state is an expression of feelings resulting from loss in struggles of life generally with loss of social rank. Gilbert and Allan (1998) developed the defeat scale (DS) with the objective of evaluate the defeat severity. The psychometric properties of DS were assessed in a group of students $(n=609)$, a group from general population $(n=406)$ and another of patients with major depression $(n=106)$. The scale revealed a one-dimensional structure in factor analysis and a good internal consistency between .89 and .93 in the three groups and in both genders. The test-retest stability, the convergent validity with depressive symptomatology, the divergent validity with social support and optimism, as well as the construct validity showed to be adequate. The present 
Defeat Scale version showed adequate psychometric qualities to be applied in clinical and in healthy populations.

KEY-WORDS: Defeat Scale, Psychometric Properties, Evolutionary Psychopathology.

\section{Défaite - concept et de l'évaluation: Les propriétés psychométriques de la version Portugaise de l'échelle de défaite}

La théorie de la position sociale (social rank theory) dans le cadre de la psychopathologie de l'évolution suggère que la défaite est une réponse adaptative présent surtout dans les situations de conflit agonistique. Des études chez les animaux et les humains en évidence l'impact neurobiologique des situations négatives de la défaite. Chez l'homme, l'état exprime le sentiment de défaite pour les pertes résultant de la lutte pour des objectifs importants et la réduction du rang social. Léchelle de défaite (ED), a été élaborée par Gilbert et Allan (1998) afin d'évaluer l'intensité de la défaite. Les propriétés psychométriques de l'échelle ont été évaluées dans un groupe d'étudiants $(n=609)$, un groupe de la population générale $(n=406)$ et un groupe de patients avec dépression majeure $(n=106)$. L'échelle a révélé une structure unidimensionnelle de l'analyse factorielle et une bonne cohérence interne entre 0,89 et 0,93 dans les trois groupes et dans les deux sexes. La fidélité test-retest, la validité convergente avec les symptômes dépressifs et la validité divergente avec le soutien social et l'optimisme, ainsi que la validité de construit, s'est avéré suffisant. Cette version de l'échelle de défaite a montré de bonnes propriétés psychométriques pour utilisation dans les populations cliniques et non cliniques.

MOTS-CLÉS: Echelle de Défaite, Caractéristiques Psychométriques, Psychopathologie Evolutive. 
TABELAS

Tabela 1 - Médias e desvios padrão para os 4 instrumentos nas 3 amostras.

\begin{tabular}{lllllll}
\hline & \multicolumn{2}{l}{$\begin{array}{l}\text { Estudantes } \\
(\mathrm{N}=609)\end{array}$} & \multicolumn{2}{l}{$\begin{array}{l}\text { População geral } \\
(\mathrm{N}=406)\end{array}$} & \multicolumn{2}{c}{$\begin{array}{l}\text { Doentes } \\
(\mathrm{N}=106)\end{array}$} \\
\cline { 2 - 7 } & $\mathrm{M}$ & $\mathrm{DP}$ & $\mathrm{M}$ & $\mathrm{DP}$ & $\mathrm{M}$ & $\mathrm{DP}$ \\
\hline Escala de Derrota & 15.34 & 8.67 & 13.98 & 8.76 & 37.95 & 12.35 \\
BDI & 7.03 & 6.96 & 6.42 & 6.75 & 28.87 & 8.07 \\
MSPSS & 71.27 & 11.81 & 70.49 & 12.93 & 56.45 & 16.00 \\
LOT-R & 13.59 & 2.83 & 12.09 & 2.43 & 10.36 & 4.69 \\
\hline
\end{tabular}

BDI = Inventário de Depressão de Beck

LOT-R = Teste de Orientação de Vida - Revisto (Optimismo disposicional)

MSPSS = Escala Multidimensional de Suporte Social Percebido

Tabela 2 - Análise factorial com saturação dos itens da Escala de Derrota nas três amostras.

\begin{tabular}{|c|c|c|c|c|}
\hline & & $\begin{array}{l}\text { Estudantes } \\
(\mathrm{N}=609)\end{array}$ & $\begin{array}{l}\text { População } \\
\text { geral } \\
(\mathrm{N}=406)\end{array}$ & $\begin{array}{l}\text { Doentes } \\
(\mathrm{N}=106)\end{array}$ \\
\hline & $\begin{array}{l}\text { Escala de Derrota } \\
\text { Item }\end{array}$ & \multicolumn{3}{|c|}{ Saturação dos Itens } \\
\hline 1 & $\begin{array}{l}\text { Sinto que não atingi os meus objectivos } \\
\text { na vida. }\end{array}$ & .57 & .57 & .66 \\
\hline 2 & Sinto que sou uma pessoa de sucesso. (I) & .31 & .01 & .60 \\
\hline 3 & Sinto-me derrotado(a) pela vida. & .80 & .76 & .83 \\
\hline 4 & Sinto que sou um(a) vencedor(a). & .32 & .10 & .59 \\
\hline 5 & $\begin{array}{l}\text { Sinto que perdi a minha posição na socie- } \\
\text { dade. }\end{array}$ & .74 & .73 & .61 \\
\hline 6 & $\begin{array}{l}\text { Sinto que a vida me tratou como um "saco } \\
\text { de pancada". }\end{array}$ & .71 & .72 & .55 \\
\hline 7 & Sinto-me impotente perante a minha vida. & .74 & .72 & .79 \\
\hline 8 & $\begin{array}{l}\text { Sinto que a confiança em mim próprio(a) } \\
\text { desapareceu completamente. }\end{array}$ & .75 & .76 & .76 \\
\hline
\end{tabular}


9 Sinto-me capaz de lidar com o que quer que seja que a vida me apresente. (I)

10 Sinto que bati no fundo.

\begin{tabular}{|c|c|c|c|c|}
\hline 11 & Sinto-me completamente fora de acção. & .81 & .84 & .76 \\
\hline 12 & $\begin{array}{l}\text { Sinto que sou um(a) do(a)s falhado(a)s da } \\
\text { vida. }\end{array}$ & .84 & .83 & .83 \\
\hline 13 & Sinto que me dei por vencido(a). & .80 & .76 & .77 \\
\hline 14 & Sinto-me completamente incapaz. & .81 & .78 & \\
\hline 15 & $\begin{array}{l}\text { Sinto que perdi batalhas importantes na } \\
\text { vida. }\end{array}$ & .70 & .66 & 67 \\
\hline 16 & $\begin{array}{l}\text { Sinto que não tenho mais capacidade para } \\
\text { lutar. }\end{array}$ & .80 & .720 & \\
\hline & value & 7.83 & 7.24 & \\
\hline & ncia (\%) & 48.93 & 45.27 & \\
\hline
\end{tabular}

(I) = Cotados de modo inverso

Tabela 3 - Valores médios, desvio padrão, correlação item-total corrigida e alfa de Cronbach se o item for excluído da Escala de Derrota para as três amostras.

\begin{tabular}{|c|c|c|c|c|c|c|c|c|c|c|c|c|}
\hline \multicolumn{5}{|c|}{$\begin{array}{l}\text { Estudantes } \\
(\mathrm{N}=6 \circ 9)\end{array}$} & \multicolumn{4}{|c|}{$\begin{array}{l}\text { População geral } \\
\qquad(\mathrm{N}=406)\end{array}$} & \multicolumn{4}{|c|}{$\begin{array}{l}\text { Doentes } \\
(\mathrm{N}=106)\end{array}$} \\
\hline \multicolumn{5}{|c|}{$\alpha$ de Cronbach da escala $=.922$} & \multicolumn{4}{|c|}{$\begin{array}{c}\alpha \text { de Cronbach da escala } \\
=.899\end{array}$} & \multicolumn{4}{|c|}{$\begin{array}{l}\alpha \text { de Cronbach da } \\
\text { escala }=.926\end{array}$} \\
\hline Item & $M$ & DP & $r$ & $\alpha$ & $M$ & DP & $r$ & $\alpha$ & $M$ & DP & $r$ & $\alpha$ \\
\hline 1 & 1.28 & .96 & .51 & .919 & 1.41 & 1.01 & .47 & .878 & 2.39 & 1.18 & .61 & .924 \\
\hline 2 & 2.08 & .86 & .34 & .923 & 1.90 & .99 & .11 & .894 & 2.88 & .98 & .55 & .925 \\
\hline 3 & .77 & .91 & .74 & .912 & .73 & .96 & .68 & .869 & 2.27 & 1.31 & .79 & 919 \\
\hline 4 & 2.18 & .94 & .34 & .923 & .90 & 1.03 & .23 & .890 & 2.75 & 1.13 & .54 & .925 \\
\hline 5 & .69 & .88 & .68 & .919 & .56 & .87 & .66 & .871 & 1.84 & 1.24 & .56 & .925 \\
\hline 6 & .62 & .91 & .64 & .921 & .62 & .94 & .61 & .872 & 2.18 & 1.32 & .49 & .926 \\
\hline 7 & .80 & .97 & .68 & .912 & .73 & .96 & .64 & .871 & 2.36 & 1.16 & .74 & .920 \\
\hline 8 & .95 & 1.03 & .70 & .921 & .67 & .97 & .68 & .869 & 2.48 & 1.24 & .71 & .921 \\
\hline
\end{tabular}




\begin{tabular}{llllllllllllll}
9 & 2.00 & .99 & .26 & .914 & 1.87 & 1.21 & .14 & .897 & 2.08 & 1.08 & .30 & .931 \\
10 & .58 & .92 & .73 & .915 & .44 & .82 & .68 & .870 & 2.25 & 1.34 & .55 & .926 \\
11 & .60 & .87 & .75 & .913 & .42 & .72 & .75 & .869 & 2.28 & 1.21 & .71 & .921 \\
12 & .50 & .82 & .78 & .913 & .32 & .71 & .74 & .870 & 1.94 & 1.29 & .79 & .919 \\
13 & .58 & .85 & .74 & .926 & .42 & .76 & .66 & .871 & 1.84 & 1.22 & .71 & .921 \\
14 & .54 & .81 & .75 & .912 & .34 & .69 & .69 & .871 & 1.81 & 1.29 & .85 & .917 \\
15 & 1.03 & .98 & .64 & .911 & 1.12 & .94 & .59 & .873 & 2.27 & 1.08 & .61 & .924 \\
16 & .66 & .95 & .73 & .911 & .52 & .82 & .64 & .872 & 2.23 & 1.31 & .73 & .920 \\
\hline
\end{tabular}

$r=r$ item-total

$\alpha=$ Alfa de Cronbach

Tabela 4 - Coeficientes de correlação $r$ de Pearson entre a Escala de Derrota e o BDI, MSPSS e LOT-R.

\begin{tabular}{llll} 
& $\begin{array}{l}\text { Estudantes } \\
(\mathrm{N}=608)\end{array}$ & $\begin{array}{l}\text { População Geral } \\
(\mathrm{N}=406)\end{array}$ & \multicolumn{1}{c}{$\begin{array}{l}\text { Doentes } \\
(\mathrm{N}=106)\end{array}$} \\
\hline Validade convergente & & $.66^{* *}$ & $.68^{* *}$ \\
BDI & $.45^{* *}$ & & \\
Validade Divergente & & $-.33^{* *}$ & $-.31^{*}$ \\
MSPSS & $-.48^{* *}$ & $-.26^{* *}$ & $-.56^{* *}$ \\
LOT-R & $-.35^{* *}$ & &
\end{tabular}

$\mathrm{BDI}=$ Inventário de Depressão de Beck.

MSPSS = Escala Multidimensional de Suporte Social Percebido.

LOT-R = Teste de Orientação de Vida (Optimismo disposicional)

Tabela 5- Médias, desvios padrão, testes $\mathrm{F}$ univariados e comparação entre grupos para as três amostras para a Escala de Derrota

\begin{tabular}{|c|c|c|c|c|c|c|c|c|}
\hline \multicolumn{2}{|c|}{$\begin{array}{l}\text { Estudantes } \\
(\mathrm{N}=609)\end{array}$} & \multicolumn{2}{|c|}{$\begin{array}{l}\text { População } \\
\text { geral } \\
(\mathrm{N}=406)\end{array}$} & \multicolumn{2}{|c|}{$\begin{array}{l}\text { Doentes } \\
(N=106)\end{array}$} & \multirow[t]{2}{*}{$F$} & \multirow[t]{2}{*}{$p$} & \multirow[t]{2}{*}{ Post-hoc } \\
\hline M & DP & $M$ & DP & $M$ & DP & & & \\
\hline
\end{tabular}

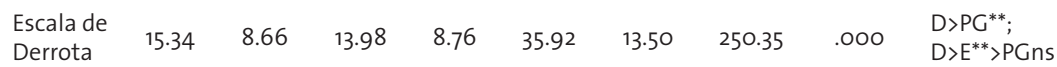

\footnotetext{
$\overline{{ }^{* *} p}<.001 ; n s=\mathrm{Não}$ significativo
} 